\title{
Rancangan Basis Data Sistem Informasi Usaha Kesehatan Sekolah
}

\author{
Fery Fadly \\ Poltekkes Kemenkes Tasikmalaya \\ Tasikmalaya, Indonesia \\ fery.fadly@dosen.poltekkestasikmalaya.ac.id
}

\author{
Syifa Pramudita Faddila \\ Universitas Buana Perjuangan Karawang \\ Karawang, Indonesia \\ syifa.pramudita@ubpkarawang.ac.id
}

\begin{abstract}
Abstrak - Usaha Kesehatan Sekolah (UKS) merupakan upaya mendasar untuk meningkatkan derajat kesehatan peserta didik yang dilaksanakan di setiap tingkat pendidikan. Tiga program pokok atau trias UKS mencakup pelayanan kesehatan, pendidikan kesehat an dan pembinaan lingkungan sekolah sehat. Dengan pentingnya keberadaan UKS juga membantu puskesmas dan dinas kesehatan untuk melakukan pemantauan terhadap tumbuh kembang peserta didik, oleh karena itu pengelolaan UKS memerlukan perancangan sistem usaha kesehatan sekolah yang bertujuan untuk deteksi dini masalah kesehatan anak, terutama mengenai gizi pada anak sekolah dasar di Kota Jambi. Metode perancangan ini menggunakan model SDLC yang beracuan pada kebutuhan data dasar dan data yang dibutuhkan dari pihak yang terlibat dalam pelaksanaan kegiatan UKS. Hasil rancangan basis data ini membentuk database informasi diri dan riwayat kesehatan peserta didik, kemudian petugas akan memeriksa berat badan, tinggi badan, tanda-tanda vital dan pemeriksaan lain yang diperlukan untuk mendukung data gizi pada anak sekolah dasar. Dengan adanya rancangan basis data sistem informasi usaha kesehatan sekolah, semoga bisa membantu pihak puskesmas dan dinas kesehatan untuk melakukan screening masalah gizi pada anak sekolah dasar.
\end{abstract}

Kata kunci - basis, data, database, informasi, system, kesehatan, sekolah, usaha, UKS

\section{PENDAHULUAN}

\section{A. Latar Belakang}

Perkembangan ilmu pengetahuan dan teknologi telah berkembang pesat, terutama pada bidang teknologi informasi. Dengan meningkatnya pertumbuhan teknologi informasi, maka penggunaan informasi tidak hanya sebatas di media kertas. Hampir semua perusahaan, organisasi, lembaga, bahkan tingkat pendidikan memerlukan mengakses data dan informasi yang tepat dan akurat. Salah satunya di sektor kesehatan terutama kesehatan di sekolah. Chaundry berpendapat bahwa sebuah perkembangan teknologi dan informasi yang dapat memberikan data yang berkualitas efisien juga dapat menghemat dana yang dikeluarkan [1].

Usaha kesehatan sekolah (UKS) merupakan salah satu kegiatan yang ada di hampir tingkat pendidikan. Program ini dibuat dengan tujuan meningkatkan kesehatan para peserta didik sehingga dapat menjadi lebih produktif di sekolah [2]. Sehingga dengan diterapkannya program ini diharapkan sekolah dapat lebih memperhatikan kesehatan para peserta didiknya dan begitu juga para peserta didik yang pada umumnya kurang memperhatikan masalah kesehatan mereka. Secara umum program UKS saat ini belum berjalan sesuai dengan harapan. Dimana tiga program pokok atau yang biasa disebut Trias UKS yang mencakup Pelayanan Kesehatan, Pendidikan/Penyuluhan Kesehatan maupun Pembinaan Lingkungan Sekolah Sehat masih dalam katagori kurang baik [3]

Hal tersebut dimungkinkan karena sekolah yang menjalankan program UKS, pengelolaan datanya masih dilakukan secara manual, sehingga dapat membuat pencatatan yang kurang akurat, akibatnya perencanaan kedepannya menjadi tidak maksimal. Padahal terdapat hubungan yang sangat erat antara sumber daya manusia (SDM) dengan pelaksanaan UKS [4] Artinya, apabila SDM di UKS dapat menjalankan fungsinya dengan baik dengan meningkatkan pemahaman dan keterampilannya mengenai pengelolaan data berbasis system (tidak lagi manual), maka tidak menutup kemungkinan UKS akan berkembang lebih pesat lagi.

Selain itu UKS juga belum dapat memberikan informasi terakhir terkait kesehatan tiap peserta didik. Hal ini mengakibatkan ketika ingin mencari informasi kesehatan para siswa, membutuhkan waktu yang cukup lama, bahkan bisa tidak dapat ditemukan. Akibatnya sekolah maupun pihak terkait seperti puskesmas maupun dinas kesehatan tidak bisa melakukan screening terhadap kesehatan anak. Padahal kesehatan anak, terutama permasalahan mengenai gizi pada anak sekolah dasar sedang menjadi salah satu pusat perhatian pemerintah karena gizi anak menentukan perkembangan di masa remaja maupun dewasa. Namun kenyataannya screening kesehatan mengenai gizi belum menjadi prioritas di UKS karena keterbatasan data yang dimiliki [5]

Pengelolaan kesehatan peserta didik di sekolah terdiri dari pengelolaan status kesehatan, penyediaan infrastruktur dan lingkungan sekolah yang sehat, serta kolaborasi lintas disiplin ilmu dan lintas sektor dalam pengelolaan kesehatan peserta didik secara holistik. Hasil dari pengelolaan kesehatan peserta didik di sekolah adalah adanya jaminan bagi anak sekolah dan orang tua, dan secara umum sebagai bentuk tanggung jawab terhadap masyarakat bahwa sekolah menjamin kesehatan anak secara holistik selama mereka berada dilingkungan sekolah [6]

Penggunaan sistem informasi dan teknologi sangat ditunjang oleh sebuah sistem basis data atau penyimpanan data yang baik. Semakin baik sistem basis data yang di buat atau dirancang maka sistem informasi tentu pula akan menghasilkan sebuah informasi yang lebih baik. Untuk mengatasi permasalahan yang ada, maka diperlukannya sebuah perancangan sistem basis data agar dapat meningkatkan pelayanan kesehatan di sekolah. Dengan adanya sistem basis data maka data kesehatan peserta didik, terutama data 
mengenai gizi dapat terpantau dengan baik, apakah gizi peserta didik dalam batas normal, mengalami obesitas atau gizi kurang. Apabila dalam batas normal, maka hanya perlu diberikan penyuluhan untuk tetap menjaga berat badannya. Akan tetapi apabila peserta didik dalam kondisi obesitas maupun gizi kurang, maka perlu dilakukan tindakan lebih lanjut, seperti penyuluhan mengenai gizi seimbang, pola olahraga teratur hingga pelaporan data ke puskesmas bahkan dinas kesehatan.

\section{B. Pertanyaan Penelitian}

Pertanyaan penelitian dari penelitian ini adalah bagaimana agar tersedia rancangan basis data sistem informasi Usaha Kesehatan Sekolah (UKS) pada anak sekolah dasar di Kota Jambi?

\section{Tujuan Penelitian}

Tujuan dari penelitian ini adalah:

1. Memudahkan sekolah untuk menyimpan dan mencari database kesehatan peserta didik

2. Mempermudah sekolah, puskesmas dan dinas kesehatan untuk screening terkait permasalahan gizi pada anak usia sekolah

\section{Metodologi Penelitian}

Penelitian ini menggunakan jenis penelitian kualitatif dengan desain Software Development Life Cycle (SDLC), dimana SDLC merupakan model yang pembangunan dan pengembangnya dapat dilakukan secara cepat tetapi tetap melihat dari sisi kebutuhan pengguna [7][8]. Sebelum pembuatan sistem basis data, terlebih dahulu peneliti menentukan setiap struktur basis data yang dirancang. Struktur data itu sendiri terdiri dari table, field, record, dan key. Penelitian dilaksanakan di wilayah Kota Jambi dengan teknik pengumpulan data yang digunakan yaitu analisis system dengan model SDLC melalui wawancara mendalam menggunakan pedoman wawancara. Jenis pertanyaan berkaitan dengan kebutuhan sistem informasi untuk menampung database yang diperlukan bagi sekolah terutama mengenai permasalahan gizi demi menunjang tercapainya pelayanan UKS yang prima dan bermanfaat bagi sekolah serta pengguna lainnya seperti puskesmas dan dinas kesehatan.

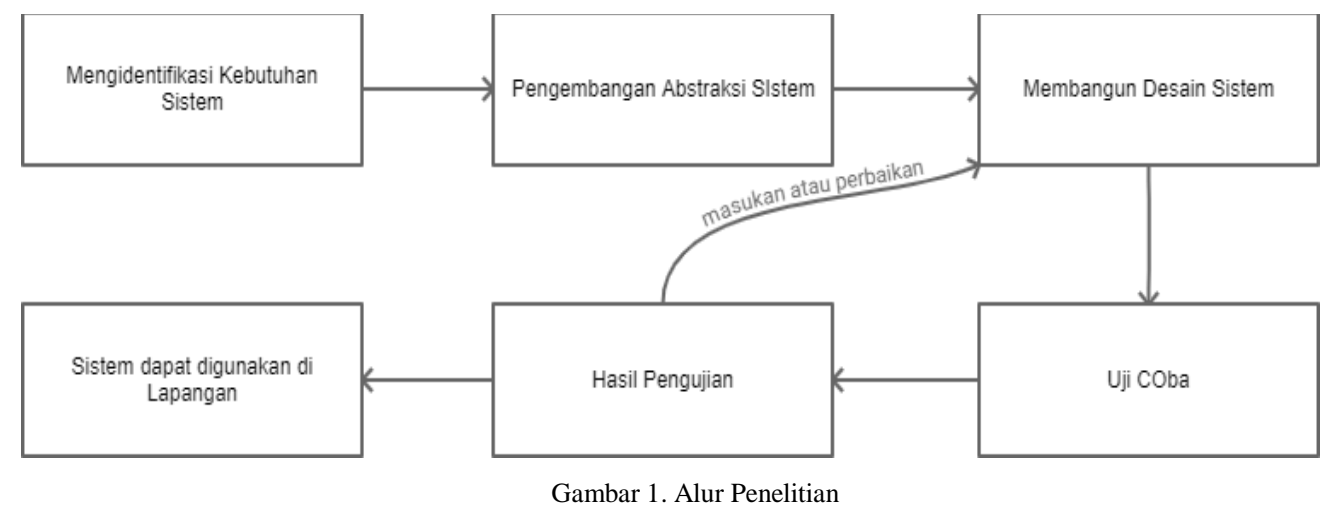

\section{HASIL DAN PEMBAHASAN}

Basis data yang dibuat dimulai dengan dibuatnya sebuah database informasi tiap siswa di sekolah dan ditambahkan informasi terkait dengan masalah kesehatan masa lalu yang pernah diderita, misal : asma, gangguan sistem saraf, dan lain-lain. Selanjutnya siswa akan diberikan kartu siswa yang akan kemudian dapat digunakan juga sebagai kartu kunjungan ke klinik sekolah. Dimana sistem database ini menggunakan nomor induk siswa untuk mengidentifikasikan siswa tersebut. Sehingga ketika siswa datang untuk berkonsultasi ataupun mendapatkan pelayanan kesehatannya hanya cukup memperlihatkan kartu siswa.

Selanjutnya petugas akan melakukan pemeriksaan terkait berat badan, tinggi badan, TTV, dan apa saja yang dibutuhkan sesuai dengan tugas pokok dari petugas kesehatan tersebut. 


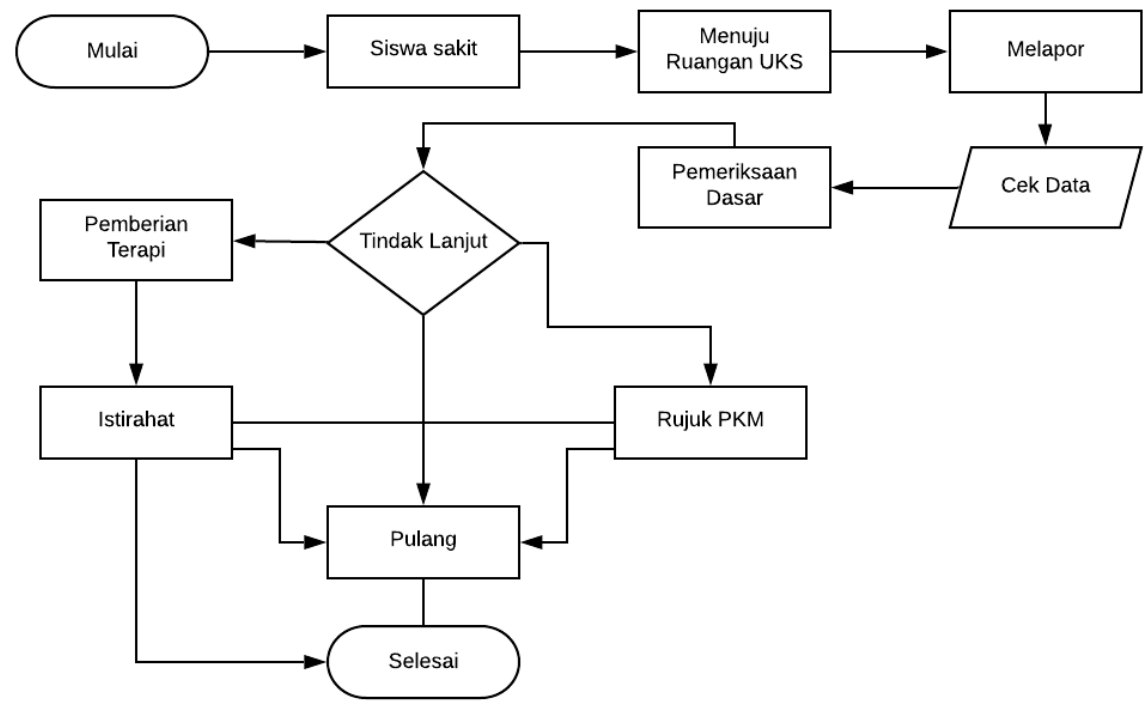

Gambar 2. Alur Proses Pemeriksaan Siswa

Petugas akan memberikan terapi yang sesuai dengan masalah kesehatan para peserta, contoh jika siswa mengalami nyeri haid, petugas dapat memberikan terapi kompres hangat dan pemberian obat pereda nyeri jika diperlukan. Jika petugas tidak dapat mengatasi masalah yang ada, maka petugas akan melakukan rujukan ke puskesmas yang menjalin kerja sama dengan sekolah atau memberikan izin pulang kepada siswa dengan persetujuan yang memiliki wewenang di sekolah.

Setiap data yang diperoleh selanjutnya akan diolah dan di analisis untuk membuat perencanaan kegiatan ataupun pemenuhan kebutuhan yang diperlukan klinik sekolah untuk menunjang pelaksanaan program UKS. Hal lain terkait dengan data base ini maka dapat melihat masalah kesehatan yang ada di sekolah sehingga pihak pengelola program UKS di sekolah dapat melakukan kerja sama dengan pihak puskesmas.

\section{A. Konteks Diagram Sistem}

Diagram konteks adalah diagram yang mencakup masukan-masukan dasar, sistem umum dan keluaran, diagram ini merupakan tingkatan tertinggi dalam diagram aliran data dan hanya memuat satu proses, menunjukkan sistem secara keseluruhan, diagram tersebut tidak memuat penyimpanan dan penggambaran aliran data yang sederhana, proses tersebut diberi nomor nol. Semua entitas eksternal yang ditunjukkan pada diagram konteks berikut aliran data-aliran data utama menuju dan dari sistem [9].

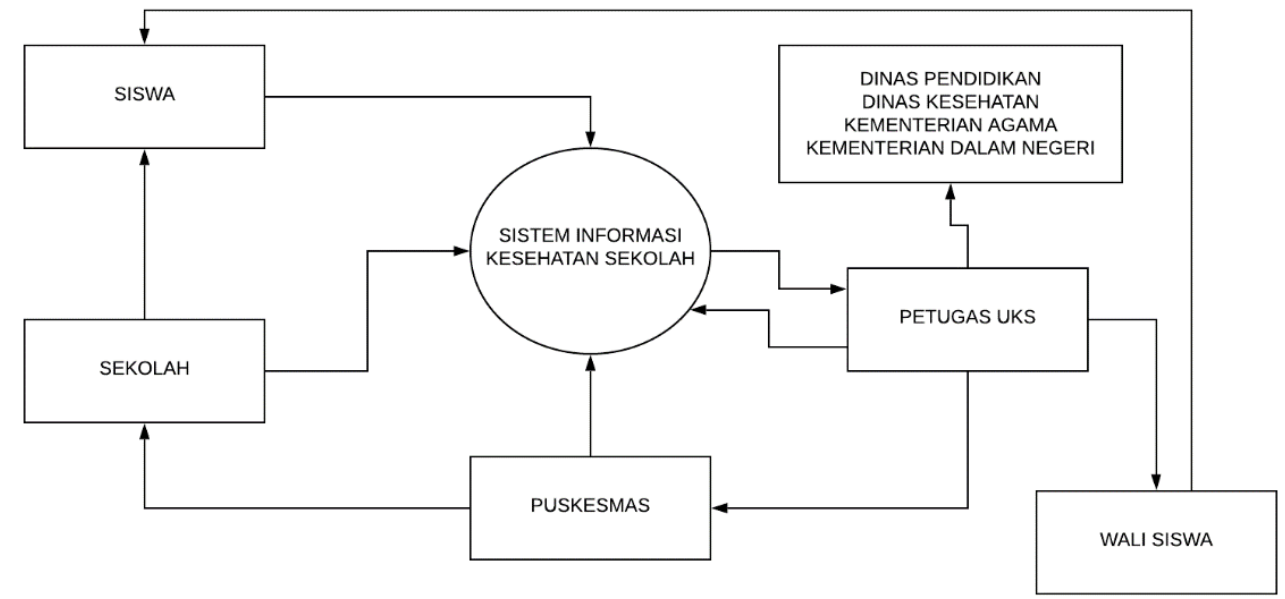

Gambar 3. Diagram Konteks Sistem Informasi Usaha Kesehatan Sekolah

Pada diagram konteks di atas menggambarkan proses alur data yang dimulai dari entitas sekolah selaku tempat menerapkan sistem ini. Kemudian entitas siswa yang kemudian semua data yang dibutuhkan seperti data yang terkait dengan registrasi siswa dan masalah kesehatan dimasukan dan di olah di sistem basis data kesehatan sekolah. Yang mana data yang telah di olah ini kemudian di gunakan oleh petugas UKS untuk sebagai laporan kepada setiap pihak yang terkait. 


\section{B. Entity Relational Diagram}

Entity Relationship Diagram (ERD) berfungsi untuk mendokumentasikan data dan mengidentifikasikan jenisnya, kemudian menghubungkan atau relasi antar entitas dengan menggunakan kunci pada setiap entitas yang terlibat.

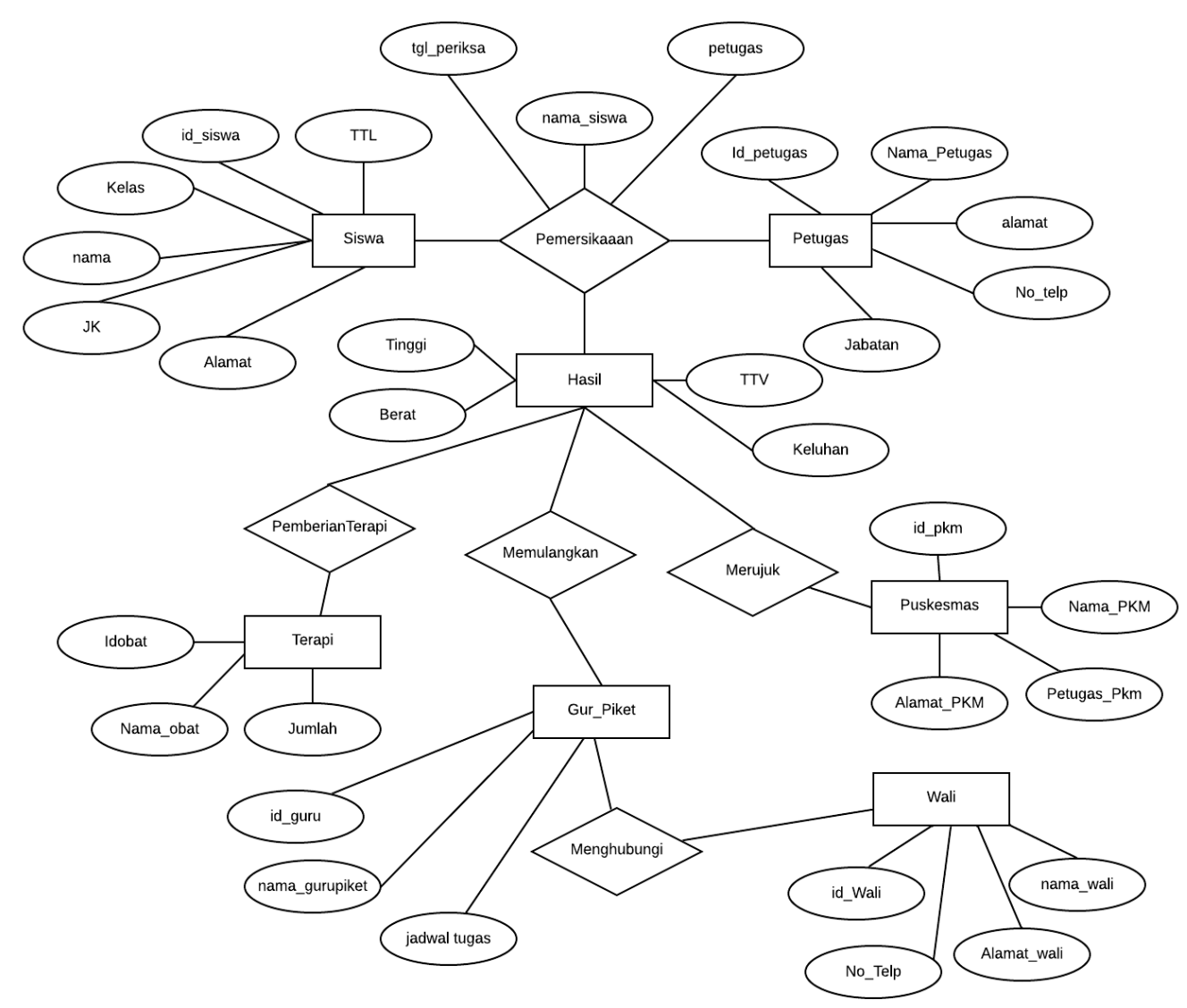

Gambar 4 . Entity Relationship Diagram (ERD) 
Techno Xplore

C. Table Relational

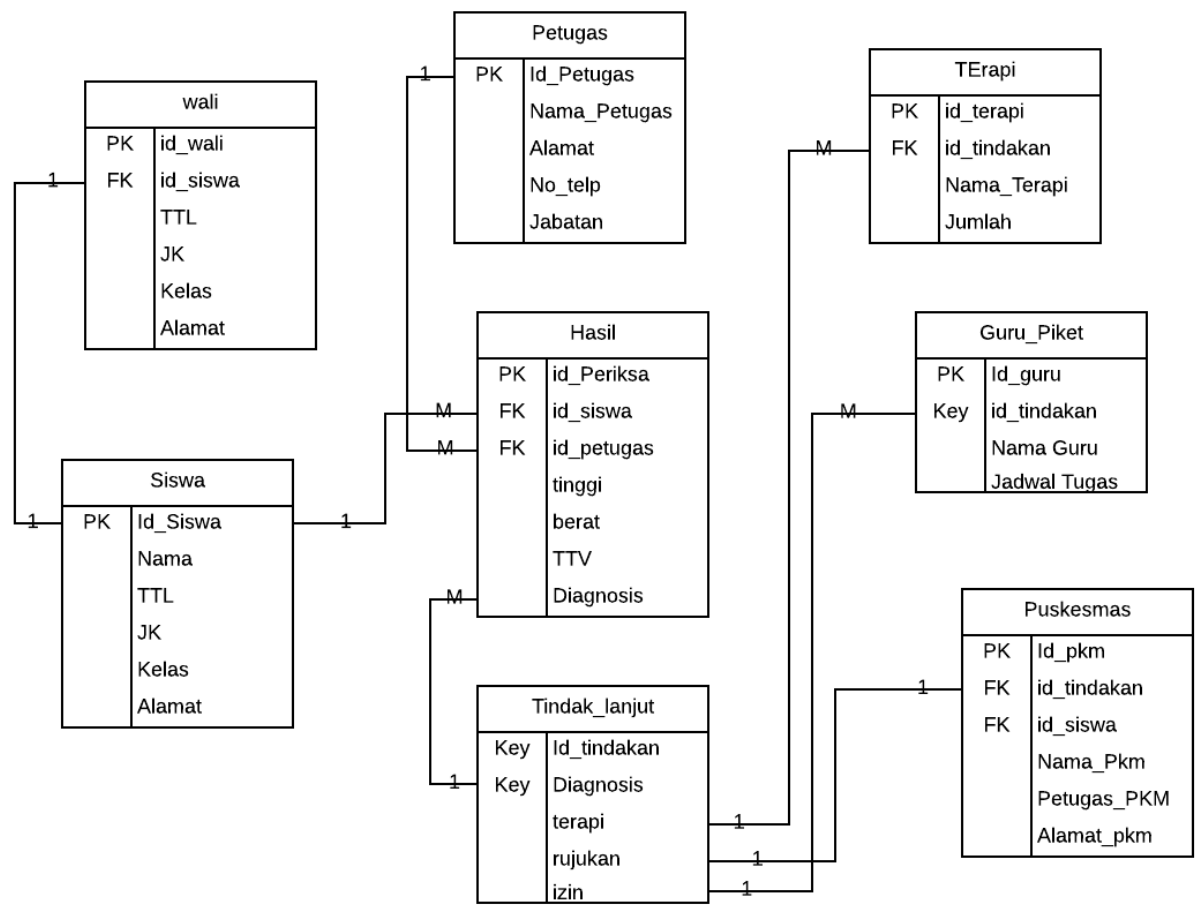

Gambar 5. Diagram Hubungan Antar Tabel

Basis data siswa berkaitan dengan jumlah data siswa di sekolah. data sekolah kemudian akan berkaitan dengan data puskesmas dan selanjutnya berhubungan dengan data dinas kesehatan dan pendidikan. Data siswa juga akan berhubungan dengan data kesehatan siswa dan data pemeriksaan kesehatan yang dilakukan oleh pihak puskesmas.

D. Kamus Data

Kamus Data Siswa

\begin{tabular}{|c|c|c|c|c|}
\hline No & Field Name & Type & Size & Description \\
\hline 1 & Id_siswa (PK) & Varchar & 8 & Nomor Induk Siswa \\
\hline 2 & Nama & Varchar & 30 & Nama Siswa \\
\hline 3 & TTL & datetime & 20 & Tempat Tanggal Lahir Siswa \\
\hline 4 & Jenis Kelamin & Varchar & 1 & Jenis Kelamin Siswa \\
\hline 5 & Kelas & Varchar & 8 & Kelas Siswa \\
\hline 6 & Alamat & Varchar & 50 & Alamat Siswa \\
\hline
\end{tabular}

Kamus Data Petugas

\begin{tabular}{|c|c|c|c|c|}
\hline No & Field Name & Type & Size & Description \\
\hline 1 & id_petugas (PK) & varchar & 8 & nomor petugas \\
\hline 2 & nama_petugas & varchar & 30 & nama petugas \\
\hline 4 & Jabatan & datetime & 15 & Jabatan / Posisi Petugas \\
\hline 5 & Alamat & varchar & 50 & Alamat Petugas \\
\hline 6 & no_telp & varchar & 15 & Nomor Telp Petugas yang dapat di hubungi \\
\hline
\end{tabular}




\begin{tabular}{|c|c|c|c|c|}
\hline No & Field Name & Type & Size & Description \\
\hline 1 & Id_wali (PK) & varchar & 8 & nama wali siswa \\
\hline 2 & Nama_wali & Varchar & 50 & Nama wali siswa \\
\hline 3 & alamat & varchar & 50 & alamat wali siswa \\
\hline 4 & no_telp & varchar & 15 & nomor telepon wali siswa yang dapat dihubungi \\
\hline
\end{tabular}

Kamus Data Hasil Pemeriksaan

\begin{tabular}{|c|c|c|c|c|}
\hline No & Field Name & Type & Size & Description \\
\hline 1 & Id_periksa & varchar & 10 & Id pemeriksaan siswa \\
\hline 2 & tinggi & varchar & 6 & Tinggi badan siswa \\
\hline 3 & Berat & varchar & 15 & Berat badan siswa \\
\hline 4 & TTV & varchar & 15 & Hasil ukur tanda tanda vital siswa \\
\hline 5 & Diagnosis & varchar & 15 & Diagnosis awal siswa \\
\hline
\end{tabular}

Kamus Data Guru Piket

\begin{tabular}{|c|c|c|c|c|}
\hline No & Field Name & Type & Size & Description \\
\hline 1 & id_gurupiket & varchar & 8 & Id guru piket yang bertugas \\
\hline 2 & nama guru piket & varchar & 15 & Nama guru piket yang bertugas \\
\hline 3 & Jadwal & varchar & 50 & Jadwal guru piket \\
\hline
\end{tabular}

Kamus Data terapi

\begin{tabular}{|c|c|c|c|c|}
\hline No & Field Name & Type & Size & Description \\
\hline 1 & id_terapi & varchar & 8 & Id terapi \\
\hline 2 & nama_terapi & varchar & 15 & Nama terapi yang diberikan \\
\hline 3 & jumlah & varchar & 3 & jumlah terapi yang diberikan \\
\hline
\end{tabular}

Kamus dataTindak Lanjut

\begin{tabular}{|c|c|c|c|c|}
\hline No & Field Name & Type & Size & Description \\
\hline 1 & id_tindakan & varchar & 15 & id tindakan yang diberikan \\
\hline 2 & diagnosis & varchar & 15 & Jenis diagnosis awal \\
\hline 3 & terapi & varchar & 15 & Pilihan terapi \\
\hline 4 & rujukan & varchar & 15 & Pilihan rujukan \\
\hline 5 & izin & varchar & 15 & Pilihan izin \\
\hline
\end{tabular}

Kamus Data Puskesmas

\begin{tabular}{|c|c|c|c|c|}
\hline No & Field Name & Type & Size & Description \\
\hline 1 & id_puskesmas & varchar & 15 & id puskesmas \\
\hline 2 & nama_pkm & varchar & 15 & nama puskesmas \\
\hline 3 & nama_petugas & varchar & 15 & nama petugas di puskesmas \\
\hline 4 & alamat & varchar & 15 & Alamat puskesmas \\
\hline
\end{tabular}




\section{KESIMPULAN}

Berdasarkan hasil uraian pada penelitian ini, maka kesimpulan diperoleh dalam penelitian ini yaitu:

1. Pengumpulan data terkait kesehatan tiap peserta didik merupakan hal yang penting dalam meningkatkan kesehatan para peserta didik itu sendiri.

2. Perancangan basis data yang baik dari sebuah system diharapkan dapat memberikan tingkat akurasi data yang baik pula. Dengan data kesehatan yang akurat, maka pemberian pengetahuan terkait informasi terutama masalah kesehatan pada peserta didik akan lebih tepat. Selain itu dengan informasi yang lebih tepat maka perencanaan kegiatan yang selanjutnya terkait dengan entitas puskesmas dan dinas lainnya. Dengan diketahuinya permasalahan kesehatan dari hasil pengumpulan di sistem basis data, maka petugas UKS dan sekolah diharapkan dapat bekerja sama dengan entitas puskesmas dalam memecahkan masalah yang ada.

3. Bagian perencanaan dapat menginformasikan kebutuhan dalam menunjang pelaksanaan kegiatan yang ada. Jika tidak dapat dipenuhi oleh pihak sekolah maka dapat dilakukan dengan pihak entitas yang lain dalam pemenuhan kebutuhan yang diperlukan.

4. Penelitian selanjutnya dapat meningkatkan perbaikan dari system yang akan di rancang disesuaikan dengan model system yang akan di bangun. Penelitian ini terbatas pada sistem basis data yang mana masih bias dilakukan penambahan atau pembaharuan data sesuai dengan kebutuhan yang diperlukan pada penelitian ini dilanjutkan. Sehingga diharapkan penelitian ini dapat berlanjut sehingga dapat memberikan sebuah sistem yang lebih baik dan dapat digunakan sesuai dengan tujuan pembuatan rancangan basis data ini.

\section{PENGAKUAN}

Tulisan ini merupakan bagian dari penelitian yang dilakukan pada perancangan system infomasi usaha kesehatan sekolah di Kota Jambi milik penulis sendiri dan dilakukan secara mandiri.

\section{DAFTAR PUSTAKA}

[1] Chaudhry B, Wang J, Wu S, Maglione M, Mojica W, Roth E, et al.(2006). Systematic review: impact of health information technology on quality, efficiency, and costs of medical care. Ann Intern Med. 2006;144:742-52.

[2] Kementerian Kesehatan RI.(2011). Pedoman Untuk Tenaga Kesehatan Usaha Kesehatan Sekolah Dasar, Sekolah Menengah Dan Pondok Pesantren

[3] Apriani, L dan Gazali, B. (2018). Pelaksanaan Trias Usaha Kesehatan Sekolah (UKS) di sekolah dasar. Jurnal Keolahragaan, 6(1), 2018, 20-28

[4] Lubis, WM. (2016). Faktor-Faktor yang Berhubungan dengan Pelaksanaan Usaha Kesehatan Sekolah (UKS) Ditingkat Sekolah Dasar Wilayah Kerja Puskesmas Pamulang Kota Tangerang Selatan

[5] Prameswari, GN. (2016). Peran UKS (Usaha Kesehatan Sekolah) Dalam Upaya Penanggulangan Obesitas Pada Anak Usia Sekolah. Journal of Health Education, Vol.1 No.2 (2016)

[6] Undang - Undang Kesehatan No. 36 tentang Kesehatan.

[7] Mcleod, R., \& Scheel, G. P. (2008). Sistem Informasi Manajemen Edisi 10. Jakarta: Salemba Empat.

[8] Hakam, F. 2016. Analisis, Perancangan, dan Evaluasi Sistem Informasi Kesehatan. Gosyen

[9] Kendall, K.E. dan Kendall, J.E. 2003. Anallisis dan perancangan Sistem. PT Prenhallindo dan Pearson Education Asia Pte. Ltd: Jakarta.

[10] Pooley, R. et all. 2013. Information System Development. First Edition. C. Schneider, ed., London: Springer Science and Bussines Media

[11] Kementerian Kesehatan RI (2011). Petunjuk Teknik Penjaringan Kesehatan Anak Sekolah Dasar. 